\title{
THE EFFECT OF $\mathrm{NiCl}_{2}$ ON THE OPTICAL PROPERTIES OF POLYVINYL ALCOHOL FILMS
}

\author{
Wasan Al-Taa'y ${ }^{1}$, Mohammed Abdul Nabi ${ }^{1}$, Emad Yousif ${ }^{2}$ \\ 1Department of Physics, College of science, AL-Nahrain University, Baghdad-Iraq \\ 2Department of Chemistry, College of science, AL-Nahrain University, Baghdad-Iraq
}

\begin{abstract}
Optical properties of pure and doped polyvinyl alcohol (PVA) films, prepared by using casting technique, with different Nickel Chloride concentrations have been studied. Parameters such as absorption coefficient, refractive index, extinction coefficient and infinitely high frequency dielectric constant were studied in the spectral range (350800) $\mathrm{nm}$.
\end{abstract}

Keywords: $\mathrm{PVA}$, polymers, $\mathrm{NiCl}_{2}$ Nickel Chloride, Optical properties.

\section{INTRODUCTION}

Polymeric materials have attracted the scientific and technological researchers, this is mainly due to their wide industrial applications. PVA is one of the earliest and best known polymers. PVA was seen as a replacement for glass in a variety of applications and is currently used extensively in glazing applications. The material is one of the hardest polymers, and is rigid, glass-clear with glossy finish and good weather resistance. PVA is naturally transparent and colorless.

Poly(vinyl alcohol) (PVA) is one of the most important polymeric materials as it has many applications in industry and is of relatively low cost in manufacture [1]. Recently, optical properties of solvent cast polymer have received considerable attention. Sharaf et. al., [2] studied the optical properties of PVA films doped with lead acetate, Abd El-Kader et. al. [3] studied the effect of molecular weights on the optical and mechanical properties of PVA films, Machell et. al. [4] studied the optical properties of thicker polymer films using different casting techniques. Chang and Whang, [5] have used PVA-based polymer as emissive layers in polymeric light emitting diodes. He showed that by adjusting the weight ratios he obtained a series of PVA polymer with different $\pi$-conjugated chain lengths, therefore the light emission can be tuned from yellow-green to blue. The transmission for visible light is very high. In the study of physical properties of polymers, the optical absorption spectrum is one of the most important tools for understanding band structure, electronic properties, and optical constants (refractive and absorption indices) of pure and doped polymers [6].

Analysis of the absorption spectra in the lower energy part gives information about atomic vibrations while the higher energy part of the spectrum gives knowledge about the electronic states in the atom. There are many researches on the optical properties of polyvinyl alcohol doped PVC-PVA thin films [7]. Optical properties of pure and doped PVA-CO-P4VPNO polymer films have been studied [8] and thermal, electrical 
and optical properties studies on the PVA based polymer electrolytes [9].

Various research groups have studied the optical, structural and other properties of PVA films doped with multiple valance metal ions such as, I/KI, $\mathrm{CuCl}, \mathrm{ZnSe}, \mathrm{CdS}$, $\mathrm{MnCl}_{2}, \mathrm{MgBr}_{2}, \mathrm{CrF}_{3}, \mathrm{FeCl}_{3}$, etc. These researches showed that a strong dependence of donor-acceptor mechanism between the metal ion and the polymer matrix. Also, these studies shows, the changes in the properties like crystallinity, structural and optical behavior of the polymer due to doping [10]. The aim of this work is to investigate the optical properties of pure and doped PVA films with different concentration of $\mathrm{NiCl}_{2}$.

\section{EXPERIMENTAL}

Polyvinyl alcohol (PVA) with molecular weight $(10000 \mathrm{~g} / \mathrm{mol})$ supplied by (SigmaAldrich Company), doped with $\left(\mathrm{NiCl}_{2}\right)$ salt. The (PVA) films with different weights of $\left(\mathrm{NiCl}_{2}\right)$ salt were prepared by dissolving (PVA) and $\left(\mathrm{NiCl}_{2}\right)$ in acetone with stirring the solution, using a magnetic stirrer for about $(30 \mathrm{~min})$ at room temperature for complete dissolving. The solution was poured in to a clean glass plate and kept till dried (3days) at room temperature. The thickness of the produced films was (160 $\mu \mathrm{m})$.

Optical transmittance and absorbance were recorded in the wavelength range (350$800 \mathrm{~nm})$ using computerized UV-visible spectrophotometer (Shimadzu UV-1601 PC). Optical transmittance and absorbance were reported in order to study the effect of doping on the parameters under investigation.

\section{RESULTS AND DISCUSSION}

The UV-VIS absorbance and transmittance spectrum in the region (350-800 nm) for doped and undoped films are shown in Figure (1). It is clear from the figure that the absorption spectra for all films decreased with increasing wavelength. While for the doped films with concentrations of $(5,10$, $15,20) \mathrm{wt} \%$ (b, c, d, e) respectively, the absorption increased with increasing the doping concentration of $\mathrm{NiCl}_{2}$, This is agreement with the values reported by earlier workers [11,12,13], mainly the bond between $\mathrm{Ni}$ ions with the adjacent $\mathrm{OH}$ groups increases and hence absorption. This is accordance with the Beer's Law. The absorption is proportional to the number of absorbing molecules [14].

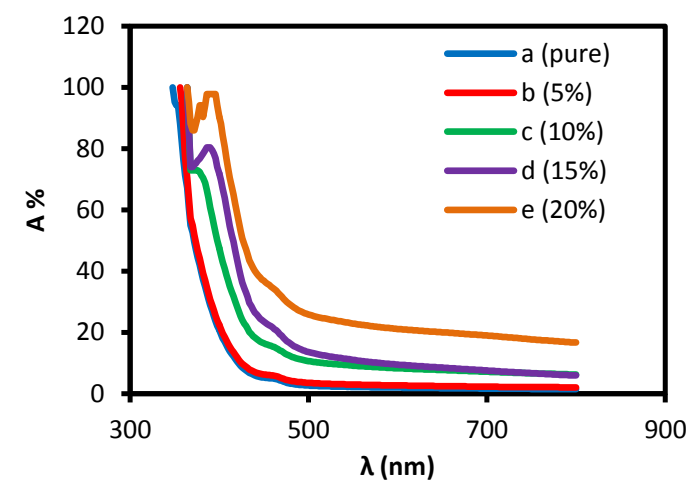

Fig.1. Absorption spectra of (a-e) PVA sample.

Figure (2) shows the transmittance spectra for all PVA films (a-e). In this figure the transmittance was increased with the increase of wavelength for all films, while after doping it can be noticed that the transmittance is decreases with increasing $\mathrm{NiCl}_{2}$ concentration. This results is agreement with reported by earlier workers $[12,15]$.

The absorption coefficient $(\alpha)$ could be calculated using the following relation [9]

$\alpha=\left(2.303^{*} \mathrm{~A}\right) / \mathrm{t}$ 


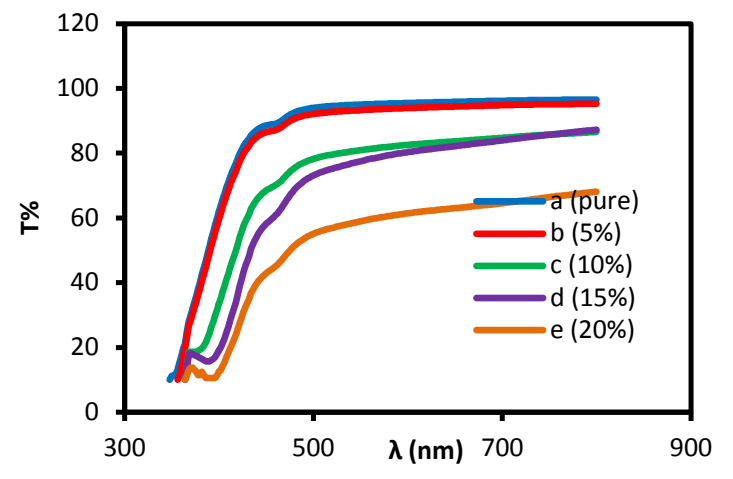

Fig.2. The transmission spectra of $\mathrm{NiCl}_{2}$ doped PVA films as function of wavelength at different concentrations.

Where $(A)$ is the absorption and $(\mathrm{t})$ is the film thickness.

Figure (3) shows the dependence of the absorption coefficient $(\alpha)$ on the wavelength. It is clear from this figure that a decreasing behavior for the absorption coefficient with increasing of the wavelength for all samples $(\mathrm{a}-\mathrm{e})$ is take place. In contrast the absorption coefficient increases with increasing the doping concentration of $\mathrm{NiCl}_{2}$ this increasing may be attributed to the difference in carrier concentration or could be related to the existence of more transmissions from higher vibration levels of the ground state to higher sublevels of the first excited singlet state [14].

The refractive index is an important parameter for optical materials and applications. Thus, it is important to determine optical constants of the films and

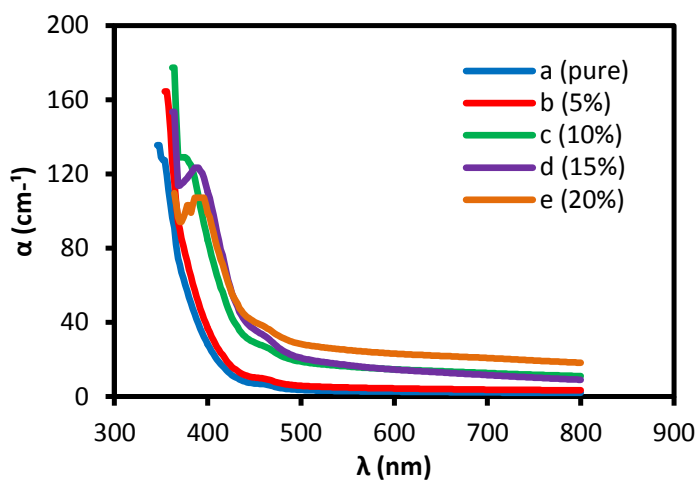

Fig.3. Variation the Absorption coefficient as a function of wavelength. the complex optical refractive index. The refractive index of the films has been determined from the transmittance R, Figure (4) shows the variation of the refractive index $\mathrm{n}$ with wavelength for all samples. The refractive index shows a decrease in the wavelength range (350-800) $\mathrm{nm}$ for ( $\mathrm{a}$ and $\mathrm{b}$ ) PVA samples while for samples (c, d, e) it shows a noticeable decreased in the wavelength range (420-800) $\mathrm{nm}$. The refractive index was increased with the increase of $\mathrm{NiCl}_{2}$ concentrations (b, c, d and e) respectively. This is in good agreement with the reported results of Faisal A [16]. The increasing in the refractive index is very useful for polymers in optics and photonics due to their ability to reduce reflection losses at interfaces [17].

The dependence of the extinction coefficient $\mathrm{k}$ on the wavelength in the range (350-800) $\mathrm{nm}$ of pure and doped samples is shown in Figure (5). It is clear that the extinction coefficient for pure PVA samples show slightly increase in the wavelengths (350-800) $\mathrm{nm}$, while it shows increase in the extinction coefficient after doping the samples (b, c, d, e) in the low wavelength range (350-420) $\mathrm{nm}$ and hence a decreases with high wavelengths.

Extinction coefficient was increased for PVA films with increasing the doping concentration (b, c, d, e) this is due to the

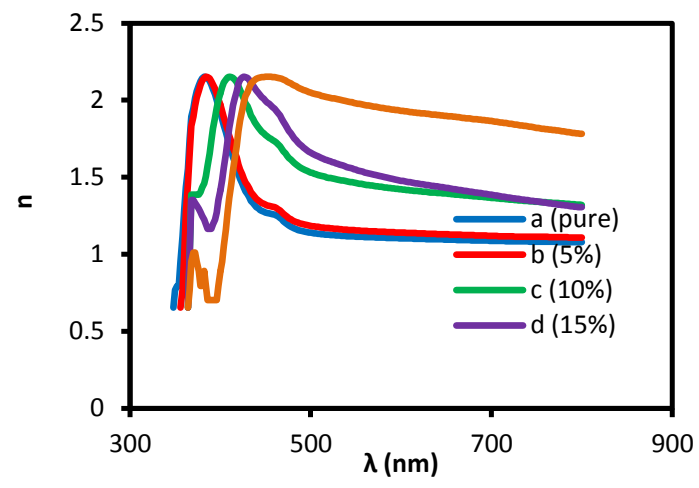

Fig.4. Variation the refractive index as a function of wavelength. 
increase in absorption coefficient, where the extinction coefficient depending on the absorption coefficient by the equation $[18,19]$.

$$
\mathrm{K}=\alpha \lambda / 4 \pi
$$

Analysis of the obtained data of refractive index can be used to obtain the infinitely high frequency dielectric constant $\varepsilon_{\infty}^{\prime}$. The dielectric constant $\varepsilon^{\prime}$ versus $\lambda^{2}$ plots shown in Figure (6), values of infinitely high frequency dielectric constant $\varepsilon_{\infty}^{\prime}$ determined from the extrapolation of these plots to $\lambda^{2}=0$ and are listed in table (1) as function of film composition. The compositional dependence of the nonlinear refractive index and dielectric constant is observed as similar to the amorphous materials. The values of average refractive index are calculated from optical constant for all the wavelength. The average value of refractive index shows the dependence on $\mathrm{NiCl}_{2}$ concentration. As shown in this figure, the infinitely high frequency dielectric constant and refractive index are decreases for samples (b and $c$ ) while they increases for samples ( $d$ and e) after doping. As well as an increases in these values with the increasing of $\mathrm{NiCl}_{2}$ concentration is obtained [20].

TABLE (1): THE INFINITELY HIGH FREQUENCY DIELECTRIC CONSTANT AND AVERAGE REFRACTIVE INDEX OF PURE AND DOPED PVA FILMS.

\begin{tabular}{|c|c|c|c|}
\hline Sample & Wt\% & $\boldsymbol{\varepsilon}_{\infty}^{\prime}$ & $\mathbf{n}$ \\
\hline $\mathrm{a}$ & Pure & 1.563 & 1.250 \\
\hline $\mathrm{b}$ & 5 & 1.317 & 1.147 \\
\hline $\mathrm{c}$ & 10 & 1.43 & 1.195 \\
\hline $\mathrm{d}$ & 15 & 2.489 & 1.577 \\
\hline $\mathrm{e}$ & 20 & 3.017 & 1.736 \\
\hline
\end{tabular}

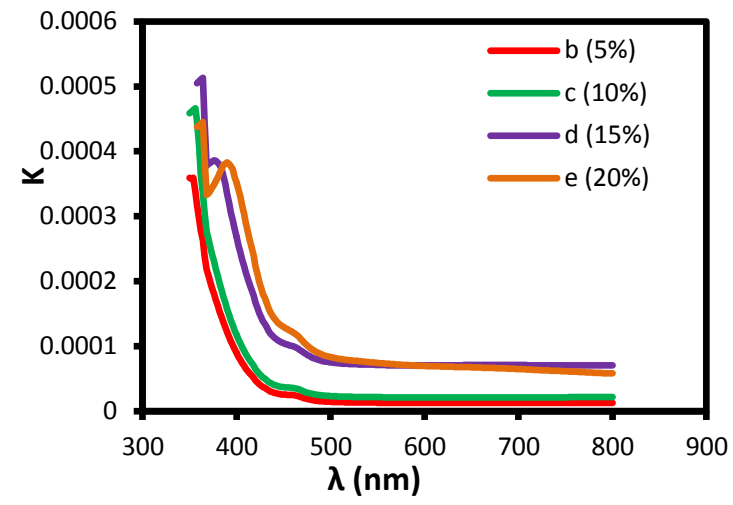

Fig.5. Variation the extinction coefficient as a function of wavelength.

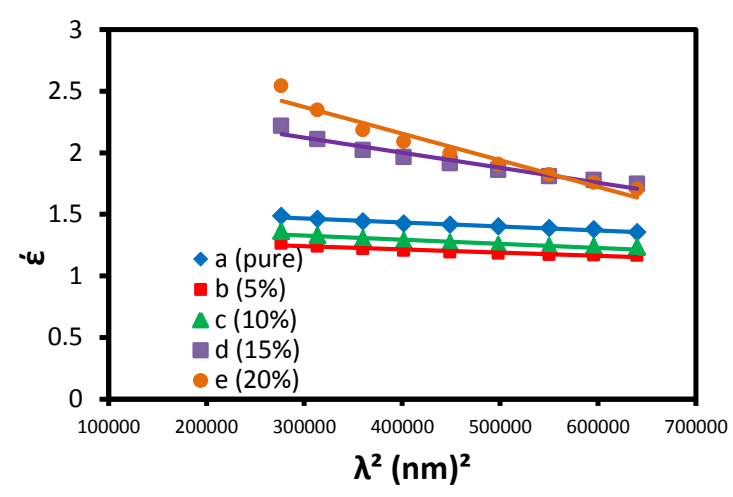

Fig.6. dielectric constant as a function of square wavelength.

\section{CONCLUSIONS}

The results indicate that $\mathrm{NiCl}_{2}$ can effectively dope PVA and enhance its optical properties. The presence of $\mathrm{NiCl}_{2}$ leads to increase the absorption and decrease the transmission as $\mathrm{NiCl}_{2}$ concentration increases. The refractive index and extinction coefficient were increased with the increase of $\mathrm{NiCl}_{2}$ concentration. The dielectric constant and average refractive index values shows dependence on $\mathrm{NiCl}_{2}$ concentration.

\section{REFERENCES}

[1] Abd El-Kader K.M., Orabi A.S., Spectroscopic behavior of poly(vinyl alcohol) films with different molecular weights, Polymer Testing., 21, 591-595, 2002.

[2] Sharaf F., El-Eraki M.H.I, El-Gohary A.R., Ahmed F.M.A., The optical and mechanical properties before and after gamma irradiation of poly(vinyl alcohol) films doped with lead acetate, 
Polymer Degradation and Stability., 47, 343-348, 1995.

[3] Abd El-Kader K.A., Abdel Hamied S.F., Mansour A.B., El-Lawindy A.M.Y., El-Tantaway F., Effect of the molecular weights on the optical and mechanical properties of poly(vinyl alcohol) films, Polymer Testing., 21, 847-850, 2002.

[4] Machell J.S., Creener J., Contestable B.A., Optical Properties of Solvent-Cast Polymer Films, Macromolecules., 23(1), 186-194, 1990.

[5] Chang W., Whang W., A study of the relationship between the electroluminescence characteristics and compositions of PPV-PVA polymers Polymer., 37, 3493-3499, 1996.

[6] Kurt A., Influence of $\mathrm{AlCl}_{3}$ on the optical properties of new synthesized 3-armed poly (methyl methacrylate) films, Turk J chem., 34, 67-79, 2010.

[7] Deshmukh S.H., Burghate D.K., Shilaskar S.N., Chaudhari G.N., and Deshmukh P. T., Optical properties of polyaniline doped PVC-PVA thin films, Indian Journal of pure $\&$ applied physics., 46, 344-348, 2008.

[8] Raja V., Sarma A.K., Narasimha Rao V.V.R., The optical properties of pure and doped PVACo-P4VPNO polymer films, Materials Letters., 57, 4678-4683, 2003.

[9] Han X., Liu R., Chen W., Xu Z ., Properties of nanocrystalline zinc oxide thin films prepared by thermal decomposition of electrodeposited zinc peroxide ,Thin Solid Films., 516, 4025- 4029, 2008.

[10] Lobo B., Ranganath M.R., Ravi Chandran T.S.G., Venugopal Rao G., Ravindrachary V., Gopal S., Iodine-doped polyvinylalcohol using positron annihilation spectroscopy, Phys Rev B 59.,13693, 1999.

[11] Zahr El-Deenb H., Hafez A.I., Physics-chemical stability of PVA films doped with $\mathrm{Mn}^{+2}$ ions against weathering conditions, The Arabian Journal for science and engineering., 34(1A), 1326, 2009.

[12] Wasan A., Mohammed T., Tagreed K., The MR affect on optical properties for poly (Vinyl alcohol) films, Baghdad Science Journal., 8(2), 543-550, 2011.

[13] Hamed M., Sabah H., Sarkawt A., electrical and optical properties of PVA/LiI polymer electrolyte films, Asian transections on science \&technology
(ATST ISSN:2221-4283), volume 01, issue 06, 16-20, 2012.

[14] Ahmed R.M., Optical study on poly(methyl methacrylate)/poly(vinyl acetate) blends, International Journal of photoenergy., 2009, 1-7. 2009.

[15] AL-Dahash G.AW., Hussein N.N., Ahmed B., Rafia T., The effect of biamuth oxide $\mathrm{Bi}_{2} \mathrm{O}_{3}$ on optical properties of poly-vinyl alcohol, British journal of science., ISSN 2047-3745, 4(1), 117 124, 2012.

[16] Faisal A.M., optical properties of $\mathrm{Nal}$ doped poly vinylalcohol films, physical science research international., 1(1), 1-9, 2013.

[17] Obreja P., Kusko M., Cristea D., Puric M., Comanescu F., Doped polymers controllable index-preparation, processing and applications, Proceedings of the symposium on photonics Technologies for $7^{\text {th }}$ Framework program., Wroclaw 12-14, 392-395, 2006.

[18] Omed G., Dlear R., Optical absorption of polyvinyl alcohol films doped with Nickel Chloride, Applied mechanics and materials., 110, 117-182, 2012.

[19] Al-Ramadin Y., Optical properties of poly(vinyl alcohol)/poly(ethylene oxide) blend, optical materials., 14, 287-290, 2000.

[20] Bakry A., Mahmoud S., Effect of Substrate Temperature on the Optical dispersion of sprayed Nickel Oxide, Journal of Saudi International Electronics, Communications and Photonics Conference (SIECPC), published by IEEE., 1-7. 2011. 


\section{تأثير كلوريد النيكل على الخصائص البصرية لأغثية بولي فينايل الكحول}

$$
\begin{aligned}
& \text { وسن الطائي1، محمد عبد النبي1، عماد يوسف2 } \\
& 1 \text { قسم الفيزياء - كليه العلوم - جامعة النهرين-بغدادـ العراق }
\end{aligned}
$$

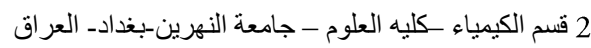

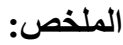

درست الخصائص البصرية لأغشية بولي فينايل الكحول النقية (PVA) و المشوبة بمادة كلوريد النيكل (NiCl2) بعد تحضير ها بأستخدام طريقة الصب وبنسب تثويب مختلفة. تم دراسة المعلمات البصرية المنثلة بمعامل الامتصاص, معامل الأنكسار, معامل الخمود, ثابت العزل بتردد عالي ضمن مدى الاطوال الموجية .$(350-800) \mathrm{nm}$ 